\title{
ERRATA EM: Revista Brasileira de Educação Médica, volume 33, número 3, Julho-Setembro 2009
}

\author{
ERRATUM IN: Brazilian Journal of Medical \\ Education, volume 33, issue 3, July-September \\ 2009
}

Erro na grafia do autor do artigo: "Experiências e impactos do aprendizado em homeopatia: relatos de médicos egressos do Curso de Especialização em Homeopatia da FMJ", Maristela Schiabel Adler, Dante Marcelo Claramonte Gallian. Revista Brasileira de Educação Médica, 33(3):356-63

Correção na grafia do autor do artigo: "Experiências e impactos do aprendizado em homeopatia: relatos de médicos egressos do Curso de Especialização em Homeopatia da FMJ", Maristela Schiabel Adler, Dante Marcello Claramonte Gallian. Revista Brasileira de Educação Médica, 33(3):356-63 